\title{
Simulation Analysis of Vertical Movement of Nitrate Nitrogen in Vadose Zone of Fluvo-aquic Soil Based on HYDRUS-1D
}

\author{
Ping Jing ${ }^{1}$, Hui Zhang ${ }^{1 *}$ \\ ${ }^{1}$ College of Geography and Environmental Sciences, Tianjin Normal University, Tianjin 300387, China
}

\begin{abstract}
Wastewater reuse has significant social, economic and ecological benefits, and has become an important measure to alleviate the water crisis. In this paper, in the simulation analysis of soil nitrate nitrogen, the method of combining soil column leaching and model simulation is used to test the accuracy of the model. The Pearson correlation coefficient is as high as 0.99 and the Nash coefficient is also over 0.9. It shows that the simulation results of the simulation model are credible. The Hydrus-1D model is used to visually simulate the change process of Tianjin fluvo-aquic soil over time. In the simulation, the process of solute migration in the $6-18 \mathrm{~cm}$ of the ground surface is basically the same, and they all reach a stable state about 4 hours, and show a linear increase trend four hours ago, and then the concentration remains stable and unchanged.
\end{abstract}

\section{Introduction}

The migration law of pollutants in the unsaturated zone has become an important content of groundwater pollution risk assessment[1]. Research on the migration mechanism and cumulative effects in the soil vadose zone can provide early warning of potential groundwater environmental pollution. In this paper, through indoor soil column experiments, the physical and chemical parameters of the fluvo-aquic soil and the vertical leaching process data are obtained, the simulation parameters are verified through the measured data, and then the Hydrus-1D model is used to simulate the vertical migration process in the vadose zone. The simulation results are input into the simulation software as the initial conditions for the next simulation to realize the quantitative simulation of the cumulative effect of multiple sewage irrigation and predict the vertical distribution law in the vadose zone.

\section{Materials and methods}

Unsaturated zone is the soil medium through which crop irrigation water can flow, and is the core area where surface water, soil water and atmospheric water transform into each other [2]. The landform type of Tianjin sewage irrigation area is a subregion of marine low plain, which belongs to a warm zone with semi-humid continental monsoon climate [3]. Fluvo-aquic soil is a basic soil type widely distributed in alluvial plains in Tianjin. The process of water and solute transport in the unsaturated zone of soil is often difficult to carry out field trials under natural conditions, because many uncertain factors have a great influence on the accuracy of the data. The simulation of the vertical migration process by the indoor soil column leaching device is simple and easy to implement. It can provide verification data for model simulation, invert the simulation analysis parameters, and determine the parameter values of the fluvo-aquic zone.

\subsection{Test design}

The indoor test soil column is a transparent organic glass column with an inner diameter of $3 \mathrm{~cm}$, a height of $50 \mathrm{~cm}$, and a total filling soil of $30 \mathrm{~cm}$. A sampling location is set at the bottom of the soil column. The diameter of the soil column used in the study is very small, it will take a short time during the leaching experiment and can fully infiltrate the soil with a short time. in order to prevent wall flow, and avoid the leaching solution staying in the soil for a short time and not fully infiltrating the soil, petroleum jelly is used on the pipe wall to prevent edge dominant flow.

Filling the bottom of the tube with clean glass beads with different diameters of less than $5 \mathrm{~cm}$ to prevent water flow from disturbing the bottom soil, and then fill the soil sample according to the actual soil bulk density of $1.5 \mathrm{~g} / \mathrm{cm} 3$. After every $10 \mathrm{~cm}$ of filling, the surface of the soil is compacted and then the filling is continued to ensure uniform soil bulk density and no clearly stratified. Fill the soil up to $30 \mathrm{~cm}$ and then fill with $5 \mathrm{~cm}$ clean glass beads of different diameters to prevent the surface soil from disturbing by adding water. The upper device is a Markov bottle with graduations, which is used to control the water head at the top of the soil column to ensure a constant water head during the test. The lower end is connected to a bottom funnel, and a rubber tube is connected to the receiving bottle to receive the leachate.

\footnotetext{
* Corresponding author: zhang hui69@163.com
} 


\subsection{Sampling and testing}

The test soil was taken from the typical sandy fluvo-aquic soil in Jinnan District, Tianjin. The soil samples were taken from the $0-40 \mathrm{~cm}$ soil layer section and brought back to the laboratory for processing. After the plant roots and debris are removed, the soil sample is naturally dried and crushed. The soil sample is sieved with a $2 \mathrm{~mm}$ aperture sieve, and the soil is discarded by the quarter method. Finally, about $4 \mathrm{~kg}$ of soil sample is left for the filling soil column and used to determine the soil background value.

Samples were taken at 1,2,3,6, and $18 \mathrm{~h}$ after the start of the single sewage irrigation experiment, and every $1 \mathrm{~h}$ after the start of the cumulative experiment, and the content in the sample solution was measured with an ultraviolet spectrophotometer.

In order to understand the characteristics of leaching loss in different time periods in a single leaching process, a single process sampling method was used to detect the soil column leaching solution. Sampling is taken every 1 hour after the start of leaching, and sampling can be extended for several hours after three samplings, because there is little difference in concentration after long-term leaching.

\section{Model construction}

Hydrus-1D is a professional and free water environment simulation software developed by the American Salt Soil Laboratory. The software contains a one-dimensional (1D) finite element model to simulate the movement of water and solutes in porous media Process, support interactive graphical interface and discretization of soil profile. The software can perform data pre-processing, structured and unstructured finite element mesh generation, and graphical display of the results. The software covers the hysteresis effects of crop root water absorption and soil water holding capacity, and can set different constant or non-constant boundary conditions, which has good applicability [4].

\subsection{The basic equation of water movement}

The simulation analysis of water in the vadose zone of fluvo-aquic soil mainly focous on the change law of the one-dimensional vertical migration process. It is assumed that the gas phase plays a very small role in the liquid flow. In this case, the one-dimensional uniform motion process of water in the vadose zone medium is described by the modified Richards equation [5].

\subsection{Soil water transport equation}

Soil hydraulic model is an important method to describe the soil water transport characteristic curve. There are six soil hydraulic models commonly used to analyze the soil water characteristic curve: (1) van Genuchten-Mualem model; (2) air Enter the van GenuchtenMualem model with a value of $-2 \mathrm{~cm}$; (3) modified van Genuchten-type equations; (4) Brooks and Corey equations; (5) Kosugi's log-normal distribution model; (6) dual porosity model.
Hydrus-1D provides the first five types of soil hydraulic models. Since the van Genuchten-Mualem model has a better fit for coarse soil and clay soil, it is currently the most widely used, so the van Genuchten-Mualem model is used for soil moisture transport [6].

\section{3 the solute transport equation}

The properties of the solute transport equation in the vadose zone are relatively stable, and it is easy to move with the irrigation water from the surface to the groundwater. The improved convection dispersion equation is used to simulate the solute transport process [7].

$$
\frac{\partial \theta \mathrm{c}}{\partial t}+\rho \frac{\partial s}{\partial t}=\frac{\partial}{\partial z}\left(\theta D \frac{\partial c}{\partial z}\right)-\frac{\partial q c}{\partial z}-\Phi
$$

In the formula, $\theta$ is the volumetric water content $\left(\mathrm{cm}^{3} \cdot \mathrm{cm}^{-3}\right)$; $\mathrm{c}$ is the liquid concentration of the soil and filler solute $\left(\mathrm{g} \cdot \mathrm{cm}^{-3}\right) ; \mathrm{t}$ is the simulation time $(\mathrm{h}) ; \rho$ is the soil bulk density $\left(\mathrm{g} \cdot \mathrm{cm}^{-3}\right) ; \mathrm{s}$ is the solid phase concentration of solute in soil and filler $\left(\mathrm{g} \cdot \mathrm{g}^{-1}\right)$; D is the comprehensive dispersion coefficient, representing molecular diffusion and hydrodynamic dispersion, reflecting the diffusion and dispersion mechanism of solute molecules in soil and filler; $\mathrm{q}$ is volume Flow flux density $\left(\mathrm{cm} \cdot \mathrm{h}^{-1}\right) ; \Phi$ is the source-sink term, which represents the various first, zero and other solutes occurring between the three phases of solid, liquid, and gas during the vertical migration process response $\left(\mathrm{g} \cdot \mathrm{cm}^{-}\right.$ $\left.3 \cdot \mathrm{s}^{-1}\right)$.

\subsection{Model parameter settings}

Changes in soil hydraulic parameters have important effects on the output variables of HYDRUS-1D, such as soil water potential and cumulative infiltration. The measured soil media data is used to determine the parameters, and the artificial neural network that comes with the software is used to analyze the physical properties of the soil to obtain the simulation parameters used in the model analysis. The model parameters can be quickly calibrated and the accuracy of model simulation can be improved.

The pedotransfer function (PTF) based on neural network is used to predict soil water retention parameters and saturated hydraulic conductivity $\left(\mathrm{K}_{\mathrm{s}}\right)$ based on structural information. According to the micrographs of soil particles, the composition ratio of sand, powder and clay is counted, and the soil composition ratio data is input into the initial estimation module of soil hydraulic parameters (see Figure 2), and the optimized parameters of the soil simulation can be directly obtained.

\subsection{Simulation boundary conditions}

In the boundary condition setting of the simulation model, for the upper boundary of solute transport, the solute flux boundary is selected, and the lower boundary is selected as the zero gradient boundary condition to calculate the soil leaching loss. The soil layer is divided into 101 units in the Z-axis direction, the time step is hours, the 
minimum time step is set to $0.001 \mathrm{~h}$, and the maximum time step is $0.1 \mathrm{~h}$. In order to better analyze the migration law in the vadose zone, this simulation sets the background value in the vadose zone as the simulated background value, and the upper boundary water concentration is set to $40 \mathrm{mg} / \mathrm{L}$.

\subsection{Model verification}

In order to evaluate the simulation accuracy of the model, through the correlation analysis of the experimental data and the simulation data, by which the validity of the model prediction results can be judged. Nash-Suttcliffe simulation effect coefficient (NSC), root mean square error RMSE and Pearson correlation coefficient $r$ were used to analyze and evaluate the accuracy of the simulation results. The value of NSC ranges from negative infinity to 1 , and the value of NSC is close to 1 , indicating that the model simulation effect is good, and the reliability of model analysis is high; when the value of NSC is close to 0 , it indicates that the simulation result is close to the average level of the observed value, indicating the model prediction result is credible in general, but the simulation error of the process is large; when the NSC value is far less than 0 , the model prediction result is not credible.

RMSE is used to measure the accuracy of simulation results, and NSC is used to measure the calculation deviation. The specific calculation formula is as follows:

$$
\begin{gathered}
R M S E=\sqrt{\frac{1}{N} \sum_{i=1}^{N}\left(x_{i}^{\prime}-x_{i}\right)^{2}} \\
N S C=1-\frac{\sum_{i=1}^{N}\left(x_{i}-x_{i}^{\prime}\right)^{2}}{\sum_{i=1}^{N}\left(x_{i}-\bar{x}_{i}\right)^{2}} \\
r=\frac{\sum_{i=1}^{N}\left(x_{i}-\bar{x}_{i}\right)\left(x_{i}^{\prime}-\bar{x}_{i}^{\prime}\right)}{\sqrt{\sum_{i=1}^{N}\left(x_{i}-\bar{x}_{i}\right)^{2} \sum_{i=1}^{N}\left(x_{i}^{\prime}-\bar{x}_{i}^{\prime}\right)^{2}}}
\end{gathered}
$$

The root mean square error RMSE can be calculated based on the measured concentration value at $30 \mathrm{~cm}$ of the soil column and the simulated value, in order to measure the accuracy of the simulated value. The smaller the RMSE, the higher the simulation accuracy, and the closer the model predicted to the actual situation. The NSC value is usually between $0-1$. The larger the NSC, the smaller the error between the simulated value and the experimental data, and the smaller the data error. When the NSC value is greater than 0.75 , the simulation result is acceptable. The Pearson correlation coefficient $r$ is used to analyze the degree of linear correlation between two variables. The value of $r$ ranges from -1 to +1 . If $r>0$, the two variables have a positive correlation; if $r<0$, It shows that the two variables have a negative correlation. The larger the absolute value of $r$, the stronger the correlation between the two undesirables. If $\mathrm{r}=0$, it means that there is a non-linear correlation between the two variables. Close to 1 or -1 is called a strong correlation [7].

\section{Analysis of results}

The results of this study are divided into two parts. The first part is to verify the agreement between the measured values of the soil column leaching process and the simulated values of Hydrus-1D to test the feasibility of the simulation parameters and determine whether the simulation results can be used for simulating. The process analysis of sewage irrigation in the soil field; the other part is the Hydrus-1D model to study the vertical migration law in Tianjin fluvo-aquic soil, quantitatively analyze the vertical distribution law of solute, and visually simulate the change process in the soil over time.

In the study, five observation points were set up for the vertical division of the vadose zone, with buried depths of $6,12,18,24$, and $30 \mathrm{~cm}$ respectively. The distribution of solutes in the vertical direction was described in a vertical equidistant manner. In the process of model simulation, all the data of different buried depths are output to reveal the law of solute movement over time on the section of the vadose zone.

\subsection{Accuracy analysis of simulation results}

According to the previous model verification method, the Nash-Suttcliffe simulation effect coefficient (NSC), root mean square error RMSE and Pearson correlation coefficient $r$ are calculated respectively, and the accuracy of the simulation results is analyzed and evaluated.

According to the measured value of the soil column leaching experiment and the model simulation value(see Figure 1), the relevant error analysis was calculated respectively. The results are shown in Table 1 . The Pearson correlation coefficient and the Nash coefficient are as high as 0.99 or more, indicating that the simulation accuracy is very high, and the parameter selection of the model conforms to the soil Ratio of particle size

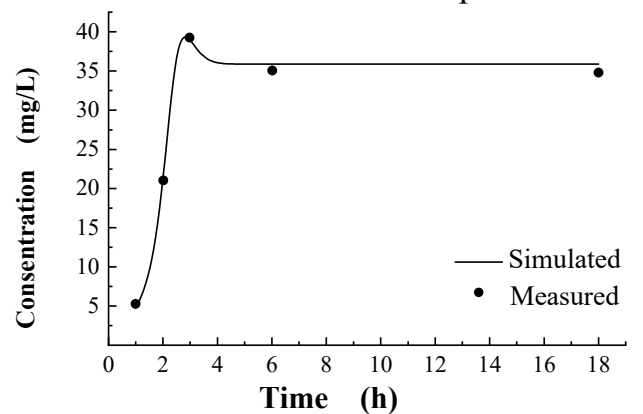

Figure 1. Measured value and model simulation value

Table1. Error analysis of measured value and simulated value

\begin{tabular}{ll}
\hline parameter & result \\
\hline Pearson & 0.9978 \\
nsc & 0.995806 \\
RMSE & 0.810939 \\
\hline
\end{tabular}

\subsection{Simulation process analysis}

The concentration increases rapidly from the beginning of irrigation, and the adsorption of pollutants by the soil 
gradually decreases. As the adsorption decreases, different depths reach the maximum adsorption value after 1-3 hours after leaching, and the desorption causes the pollutant concentration to reach the peak. After reaching the peak value, it decreased slightly, and the adsorption reached a stable state after 4 hours, and the solute maintained a certain stable value at different depths (see Figure 2). It shows that after the solute is saturated with water in the vadose zone, the adsorption and desorption reach an equilibrium state, and the concentration of soil water remains stable.

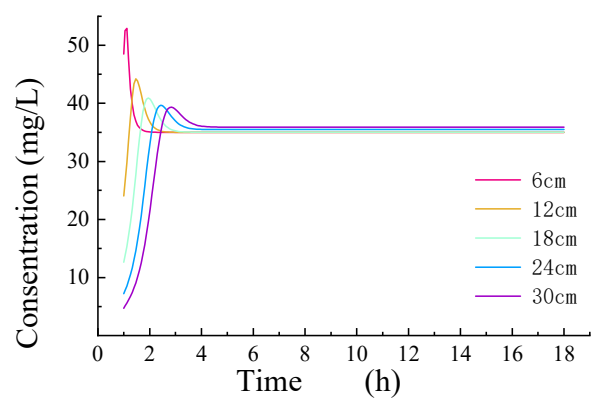

Figure 2. Model simulation process diagram

\subsection{Vertical concentration change analysis}

In the sequential process analysis using Hydrus-1D software, it can be clear that the leaching concentration value after the leaching process is stable and almost unchanged, and the most complicated process is mainly concentrated in the first 4 hours. Therefore, in order to determine vertical concentration change process, a vertical change distribution map can be displayed during the simulation process based on the simulation analysis data (see Figure 3).

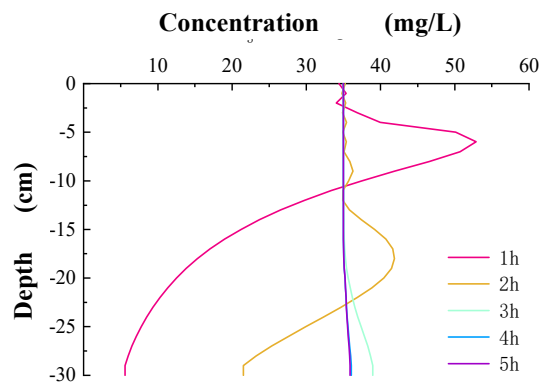

Figure 3. The vertical simulation process

During the first 1 to 2 hours of leaching, there is a process where the concentration does not change with time in the vertical direction of the soil, and then there is an increasing peak value. This process shows that there is a time course for the soil to enter the leaching solution, and then the value of the upper layer of the soil is increased, and then the concentration decreases due to the leaching loss. Up to 3 hours, the concentration has basically no longer changed in the vertical section of the soil.

\section{Conclusion}

In the soil simulation analysis, the method of combining soil column leaching and model simulation is used to test the accuracy of the model. Among them, the Pearson correlation coefficient value is greater than 0.8 , especially the value of the first two times is as high as 0.99 . The simulation accuracy is very high, and the Nash coefficient is also above 0.9 , indicating that the simulation results of the simulation model are credible.

Hydrus-1D is used to simulate the vertical migration process of soil aeration zone, and the two modules of Hydrus-1D water flow and solute migration are used to predict. The law of solute migration at $6-18 \mathrm{~cm}$ on the surface is basically the same, both in about 4 hours to reach a steady state, the concentration increases rapidly from the beginning of irrigation, and the soil's adsorption of pollutants gradually decreases. As the adsorption decreases, different depths reach the maximum adsorption value after 1-3 hours after leaching, and the desorption will increase and the concentration of pollutant reach the peak.

\section{Acknowledgments}

Authors wishing to acknowledge the financial support from Key Project of Tianjin Natural Science Foundation (18JCZDJC10090)

\section{References}

1. WANG S Q, ZHENG W B, KONG etc. Spatial distribution characteristics of nitrate in shallow groundwater of the agricultural area of the North China Plain[J]. Chinese Journal of Eco-Agriculture, 2018, 26(10).

2. LAI X M, LIAO K H, ZHU Q, etc. Feture analysis of soil water leakage and leaching of nitrogen and phosphorus in typical farmland of the Taihu Lake Basin based on the Hydrus-1D model[J]. Resources and Environment in the Yangtze River Basin, 2015, 24(09).

3. GE F Y, LIU J L, LI L W. Numerical simulation of pollutant transport in aeration zone of coastal reclamation land area based on Hydrus-1D[J]. Resource Information and Engineering, 2020,35(04)

4. Van Genuchten, M. Th. A closed-form equation for predicting the hydraulic conductivity of unsaturated soils, Soil Sci. Soc. Am. J., 1980， 44:892-898.

5. van Genuchten, M. Th. Convective-dispersive transport of solutes involved in sequential first-order decay reactions, Computers \& Geosci., 1985 , 11(2):129-147.

6. WANG X D, FENG W, WANG W K etc. Migrating and Transforming Rule of Nitrogen in Unsaturated Zone in Guanzhong Basin Based on HYDRUS -1D Model[J]. Geographical survey and research, 2015,38(04):291-298+304.

7. ZHANG Y H, ZHOU B B, CHEN X P etc. Effect of nano carbon on soil moisture movement characteristics in the loess slopes Based on Hydrus simulation[J]. Research of Soil and Water Conservation, 2020,27(01):132-138. 